\title{
THE INNOVATIVE WAY TO ENSURE TRANSPARENCY OF AGRICULTURAL INSURANCE IN RUSSIA AND ABROAD
}

\author{
Marina S. Uskova \\ Volgograd State University, Volgograd, Russian Federation
}

\begin{abstract}
Introduction: in the process of implementation of the legal relations under the contract of agricultural insurance common questions and disputes inevitably arise, such as the ones related to both the assessment of the risk of the object of insurance, and the subsequent analysis of the insured event. Such disputes both at the stage of conclusion of the insurance contract and in the process of its execution can and should be avoided using the modern technologies that ensure the "transparency" of legal relations between the parties. One of these technologies is space monitoring, which allows us to effectively and unambiguously resolve these disputes, providing timely and reliable information about the state of agricultural land, weather conditions and other data. What is the global experience of using this innovation? Is this experience of this country in the field of agricultural insurance in demand? The authors have tried to give the answers to these and other questions by means of the present scientific research. Methods: the methodological framework for this study is a set of methods of scientific knowledge, among which the main are the methods of consistency, analysis and the comparative law method. Results: the analysis of introducing the innovations in the field of agricultural insurance, namely, space monitoring in the North American continent, in Europe, India, China and other countries, as well as the genesis of the use of these technologies in this country, is conducted. Conclusions: it is established that the data of the Earth remote sensing serve as "transparency" of the legal relations of the parties to the agricultural insurance contract, in whose connection this innovation should be enshrined in the current legislation of the Russian Federation.
\end{abstract}

Key words: innovation, space monitoring, agricultural insurance contract, state support.

Citation. Uskova M.S. The Innovative Way to Ensure Transparency of Agricultural Insurance in Russia and Abroad. Legal Concept, 2018, vol. 17, no. 4, pp. 45-52. DOI: https://doi.org/10.15688/lc.jvolsu.2018.4.6

\section{ИННОВАЦИОННОЕ ОБЕСПЕЧЕНИЕ «ПРОЗРАЧНОСТИ» СЕЛЬСКОХОЗЯЙСТВЕННОГО СТРАХОВАНИЯ В РОССИИ И ЗА РУБЕЖОМ}

\author{
Марина Сергеевна Ускова \\ Волгоградский государственный университет, г. Волгоград, Российская Федерация
}

\begin{abstract}
Введение: в процессе реализации правоотношений по договору сельскохозяйственного страхования неизбежно возникают вопросы и споры, связанные как с оценкой степени риска предмета страхования, так и с последующим анализом наступившего страхового случая. Подобных споров как на стадии заключения договора страхования, так и в процессе его исполнения можно и нужно избегать, используя современные технологии, обеспечивающие «прозрачность» правоотношений сторон. Одной из таких технологий является космический мониторинг, который позволяет эффективно и однозначно разрешать указанные споры, предоставляя оперативную и достоверную информацию о состоянии сельскохозяйственных угодий, о погодных условиях и другие данные. Каков мировой опыт использования данной инновации? Востребован ли данный опыт нашей страной в сфере сельскохозяйственного страхования? На эти и другие вопросы мы постарались дать ответы посредством настоящего научного исследования. Методы: методологическую основу данного исследования составляют совокупность методов научного познания, среди которых основное место занима(2) ют методы системности, анализа и сравнительно-правовой. Результаты: проведен анализ внедрения в сфе-
\end{abstract}


ру агрострахования инноваций, а именно космического мониторинга на Северо-Американском континенте, в странах Европы, Индии, Китае и других странах, а также исследован генезис использования данных технологий в нашей стране. Выводы: установлено, что данные дистанционного зондирования Земли служат «прозрачности» правоотношений сторон договора сельскохозяйственного страхования, в связи с чем данную инновацию необходимо закрепить в действующем законодательстве РФ.

Ключевые слова: инновация, космический мониторинг, договор сельскохозяйственного страхования, государственная поддержка.

Цитирование. Ускова М. С. Инновационное обеспечение «прозрачности» сельскохозяйственного страхования в России и за рубежом // Legal Concept = Правовая парадигма. - 2018. - Т. 17, № 4. - C. 45-52. - DOI: https://doi.org/10.15688/lc.jvolsu.2018.4.6

\section{Введение}

Страхование в сфере сельского хозяйства нашей страны является одним из действенных инструментов поддержки отечественных аграриев и развития аграрной отрасли России в целом.

Однако в процессе реализации правоотношений по договору сельскохозяйственного страхования неизбежно возникают вопросы, связанные как с оценкой степени риска предмета страхования, так и с последующим анализом наступившего страхового случая.

В ряде правовых ситуаций страховщики отказываются признать страховой случай, нанесший ущерб фермеру, таковым, если есть ошибки или несоответствия в представленных документах и расхождение в юридически значимых данных. Иногда возникают проблемы с представленными страховой организации фотоматериалами, которые либо являются недостаточно четкими, либо могут быть сфальсифицированы (например, одни и те же снимки используются для обоснования гибели урожая в разных хозяйствах), или на представленных фотоматериалах не видно панорамы поля и возделываемых на нем культур.

Подобных споров как на стадии заключения договора страхования, так и в процессе его исполнения можно и нужно избегать, используя современные технологии, обеспечивающие «прозрачность» правоотношений сторон.

При всем разнообразии программ аграрного страхования в мире ни одна из них не способна функционировать без сбора и обработки достоверных данных производственного и погодного характера [10].

Для разрешения данных задач на сегодняшний день многими государствами приня- то решение о внедрении инноваций в процесс агрострахования.

Данные произведственного и погодного характера лежат в основе актуарных расчетов, с помощью которых разрабатывается страховой продукт и рассчитываются страховые тарифы. Большой опыт в формировании баз данных для актуарных расчетов накоплен в Канаде и США.

С началом эры освоения околоземного космического пространства в конце 1950-х начале 1960-х гг. появилась и новая отрасль дистанционное зондирование Земли (ДЗ3) из космоса. Вслед за этим активно начала разрабатываться и методика дешифрирования снимков. Используемые вначале исключительно в военных целях космические снимки очень скоро обратили на себя внимание ученых и бизнес-сообщества как источник очень ценной и полезной информации. Отрасль ДЗ3 стала бурно развиваться, съемочная аппаратура - совершенствоваться, появились новые технологии, в том числе мультиспектральная и гиперспектральная, радарная (радиолокационная) съемка земной поверхности из космоса. Стали создаваться специальные, в том числе и коммерческие, спутники Д33 [3].

Эффективное управление агропромышленным комплексом на различных уровнях требует наличия оперативной и достоверной информации о состоянии сельскохозяйственных угодий. Практически вся информация о сельском хозяйстве имеет пространственный характер, поэтому все большее практическое применение в мониторинге сельскохозяйственных земель получают геоинформационные технологии на основе использования данных дистанционного зондирования Земли.

Использование ДЗ3 позволяет получать объективную и своевременную информацию 
о состоянии сельскохозяйственных земель на больших территориях [1].

Наибольшего распространения Д33 в агропромышленном комплексе (особенно в растениеводстве) в целом и в сельскохозяйственном страховании в частности получило во многих странах мира: США, Канаде, странах ЕС, Индии, Японии, Китае и др.

В российском сельскохозяйственном страховании данная инновация находится в стадии своего становления и начинает приобретать справедливую востребованность.

\section{Использование}

\section{космического мониторинга}

\section{в агростраховании зарубежных стран}

К наиболее известным примерам действующего в мире космического мониторинга в сфере сельскозяйственного страхования следует отнести разработанный Министерством сельского хозяйства CША проект MARS (The Monitoring of Agriculture with Remote Sensing), который позволяет определять площадь посевов и урожайность, то есть те величины, без которых немыслимо заключение договора сельскохозяйственного страхования.

MARS также предназначен для обеспечения научной и технической поддержки политики Европейского союза в области сельского хозяйства и продовольственной безопасности, основанной на агрометеорологическом сельскохозяйственном моделировании, полевых обследованиях, эконометрии, геоматике (ГИС, GPS) и космическом и воздушном дистанционном зондировании Земли. Подразделение решает вопросы, связанные с общеевропейской сельскохозяйственной политикой, развитием системы европейского и глобального сельскохозяйственного мониторинга и мониторинга изменения климата. Деятельность подразделения охватывает такие задачи, как независимое прогнозирование урожайности, агрострахование, контроль сельскохозяйственной деятельности, экологическая совместимость сельскохозяйственной деятельности, влияние изменения климата. Подразделение работает по международным проектам по всему миру, а не только в Европе.

В США действует также Национальная сельскохозяйственная статистическая служ- ба США (National Agricultural Statistics Service, NASS), миссия которой заключается в обеспечении актуальной, достоверной статистики для сельского хозяйства в США. Технологии и данные дистанционного зондирования Земли являются одним из главных инструментов, улучшающих точность статистических данных. NASS использует Д3З для оценки посевных площадей и создания специальных слоев сельскохозяйственного землепользования для ГИС. Также при помощи ДЗЗ производится категоризация сельхозземель по возделываемым культурам и формирование соответствующего слоя ГИС (Cropland Data Layer CDL). NASS постоянно сотрудничает с Сельскохозяйственной научно-исследовательской службой Департамента по сельскому хозяйству США (USDA) в области использования данных MODIS для раннего прогнозирования урожайности - существенной категории договора агрострахования, от четкого установления которой зависят правоотношения сторон данного договора по урегулированию убытков. Большинство собираемых данных, в том числе мониторинг и оценка сельхозкультур, предусмотрены действующим законодательством США в сфере сельхозстрахования.

В европейской системе агрострахования данные ДЗЗ не менее востребованы, а космическая деятельность в этой сфере является одной из передовых в мире. Например, во Франции в 1987 г. в Тулузе на базе аграрного университета в целях оценки сельхозугодий создана компания «Geosys». Первые еe проекты были посвящены космическому мониторингу сельхозкультур сначала в самой Франции, потом в Испании и Португалии, результаты использовались для европейского государственного регулирования [7]. Данная компания стала первым цифровым партнером, созданным самими агрономами. Глобальные данные космомониторинга позволяют одновременно осуществлять учет локальных особенностей конкретных территорий. Во Франции при наступлении крупных убытков часть потерь фермерам возмещают страховщики, но часть напрямую возмещается государством. В этом случае также используются данные космического мониторинга состояния посевов, чтобы определить глубину убытков и уточнить необходимый объем расходов на компен- 
сации. Допустим, аграрии запрашивают 10 млн евро для возмещения ущерба по гибели урожая, а данные космомониторинга позволяют сделать объективную оценку потерь на уровне 7 млн евро. Объективные данные становятся, таким образом, основанием для вынесения справедливого решения.

За свою историю компания Geosys не раз исполняла роль аграрного «космического ока» для правительств многих стран. Так, во Вьетнаме возможности космического мониторинга были использованы для создания информационно-статистической базы государства по учету кофейных деревьев, в Мексике силы мониторинга были направлены на выявление посадок запрещенных культур в рамках борьбы с наркобизнесом. В Египте был проведен мониторинг сельзхозплощадей по просьбе правительства.

В 1999 г. данная компания перешла от государственной к частной деятельности, Geosys были подписаны контракты с NASA и USDA. Стало возможным проверять состояние агрокультур на отдаленных территориях, в разрезе полей, и даже появилась возможность сравнить поведение посевов на сегментах одного поля, засеянного двумя культурами. В настоящее время данная компания сотрудничает с ведующими страховыми организациями нашей страны по вопросам, связанным с заключением и исполнением договоров агрострахования.

В ряде стран (Канада, Индия, Япония, Китай и др.) Д33 широко применяется для мониторинга сельскохозяйственной деятельности и для принятия оперативных управленческих решений.

Так, в Китае исследования по применению данных Д33 для целей сельскохозяйственного мониторинга началось в конце 1970-х годов. Современная оперативная система сельскохозяйственного мониторинга в КНР включает в себя следующее: система космического сельскохозяйственного мониторинга Китая Министерства сельского хозяйства (CHARMS); система наблюдения за посевами Китая Китайской академии наук (CCWS); система мониторинга роста сельскохозяйственных культур и прогнозирования урожайности Китая в целях оптимизации сельскохозяйственного страхования. Осуществляется мониторинг изменения площадей посевов сельхозкультур, урожайности, продуктивности, роста культурных растений, засухи и других сельскохозяйственных параметров для 5 основных культур Китая.

В Индии - единственной стране в мире, с первого раза успешно запустившей к Марсу автоматическую станцию, - к тестированию точного земледелия приступили только в 2015 году. Система дифференциальной коррекции GAGAN (GPS - Aided GEO Augmented Navigation) позволяет определять местоположение с точностью до одного метра.

Среди стран-участниц СНГ следует отметить Казахстан, где накоплен значительный опыт использования космической информации для оценки состояния сельскохозяйственных культур. Здесь успешно развивается проект «Национальная система космического мониторинга для сельского хозяйства».

С этим государством Россия в сфере инноваций в космической деятельности взаимодействует наиболее активно. Как справедливо отмечает А.О. Иншакова, в области нанотехнологий успешным является партнерство России и Казахстана. В первую очередь это касается сотрудничества в космической сфере и использования космодрома «Байконур» [2].

\section{Роль космического мониторинга в аграрном страховании России}

Основами государственной политики в области использования результатов космической деятельности в интересах модернизации экономики Российской Федерации и развития ее регионов на период до 2030 г., утвержденными Президентом РФ 14.01.2014 г. № Пр51 [6], определено, что задачами государственной политики в области развертывания и функционирования инфраструктуры использования результатов космической деятельности являются, в том числе, создание перспективных технологий комплексного информационно-навигационного обеспечения и космического мониторинга; создание и ведение федерального фонда данных дистанционного зондирования Земли и продуктов их обработки, обеспечение равноправного и свободного доступа к данным дистанционного зондирования Земли юридических и физических лиц (с учетом требований законодательства Российской 
Федерации о защите государственной тайны), обеспечение его взаимодействия с другими специализированными информационными фондами Российской Федерации.

В Российской Федерации действует единая территориально распределенная информационная система дистанционного зондирования Земли (ЕТРИС ДЗЗ).

ЕТРИС создавалась в рамках федеральной космической программы 20062015 гг. и стала общефедеральным проектом по интеграции в единое геоинформационное пространство всех информационных ресурсов Д3З на территории страны, объединив унифицированными техническими стандартами всю наземную инфраструктуру, обеспечивающую прием информации, ее обработку и передачу потребителям.

ЕТРИС состоит из 13 крупных центров, которые расположены на всей территории России - от Калининграда до Хабаровска, включая арктическую зону (Мурманск, а в перспективе - Дудинка и Анадырь). Новая система координирует их работу с отечественными космическими аппаратами ДЗ3. Она позволит планировать съемку, получать и обрабатывать информацию с космических аппаратов комплексно и без привлечения дополнительных ресурсов.

Технические и программные средства ЕТРИС ДЗЗ разработаны АО «Научно-исследовательский институт точных приборов» (НИИ ТП, входит в холдинг «Российские космические системы»).

Решения и продукты компаний холдинга «Российские космические системы» набазе технологий ДЗ3 позволят прогнозировать урожайность сельскохозяйственных культур, оценивать состояние леса, выявлять несанкционированные вырубки, следить заразвитием ЧС и оценивать изменения климата Земли.

Основной задачей ДЗ3 в аграрной сфере является прогноз развития опасных для сельского хозяйства гидрологических явлений, оценка посевных площадей, проверка степени утраты (гибели) урожая сельскохозяйственных культур, определение иных обстоятельств, имеющих существенное значение при исполнении договоров сельскохозяйственного страхования [4].
Совершенствование инновационных технологий в сфере космической деятельности, на наш взгляд, должно быть воспринято российским законодателем применительно к сельскохозяйственному страхованию. Инновационные процессы в этой сфере должны охватить законодательную основу, модернизировать программы страхования и создать условия для применения современных инструментов.

При сопровождении договора страхования при урегулировании убытков важнее знать состояние культуры и отклонения в ее развитии на конкретных полях хозяйства. В этих целях, наряду с метеорологическими данными, используются и другие инструменты космического мониторинга: инструмент «История поля» позволяет оценивать состояние культуры в период вегетации по графику NDVI, а также сравнивать с показателями прошлых лет; инструмент «Сравнение полей» позволяет оценивать и сравнивать состояние одной культуры на соседних полях; деление поля на отдельные участки позволяет оценивать неоднородность в развитии культуры на поле и выявлять нарушения «технологических карт». Имеется возможность получения регулярных отчетов в виде графиков NDVI о состоянии культуры на застрахованных полях. Совокупность этих показателей позволяет страховщику делать вывод о необходимости направления эксперта для осмотра. Ранее эксперт направлялся на осмотр полей по каждому извещению от страхователя об отклонении в развитии культуры.

В настоящее время данные космического мониторинга в российском агростраховании полностью оправдали себя. Национальный союз агростраховщиков (НСA) рассчитывает заложить их в фундамент порядка урегулирования убытков и придать им официальную силу доказательств в судах.

В настоящее время НСА реализуется проект с участием ранее упомянутой нами французской компании «Geosys», который появился как нельзя кстати - в момент обострения недоверия между агростраховщиками и их клиентами-сельхозпредприятиями. Это происходило на фоне растущего числа мошенничеств со страховыми выплатами, в том числе в сегменте агрострахования. 
В случае судебных споров в сфере сельскохозяйственного страхования зачастую особо остро стоит вопрос с обеспечением доказательной базы о состоянии посевов. В НСА в этой связи особо подчеркивают, что на сегодняшний день основополагающим является достижение цели придания современным технологиям космического мониторинга официального статуса, закрепленного в действующем законодательстве в сфере агрострахования, поскольку, используя возможности мониторинга, страховщик может определить состояние развития культур по показателям вегетационного индекса, являющегося основным критерием при оценке состояния застрахованных культур. Для анализа изменений данного индекса используются метеорологические данные (такие как суточные температуры воздуха, высота снежного покрова, суточные осадки, сила ветра и другие), а также оценивается их влияние на развитие культур. Для страховщиков очень важно, что данные по этим показателям имеются за последние 17 лет и есть возможность получить прогноз на ближайшие 10 дней. Мониторинг можно проводить по многим параметрам, например, по субъектам РФ или каждому конкретному полю и на нужную дату. Поскольку данные анализа оформляются в виде отчета, материалы в электронном виде можно предоставлять аграрию (страхователю) для информации, а при урегулировании убытков использовать в качестве материалов экспертизы для выплатного дела.

С 2016 г. НСА организовал централизованный доступ для всех членов союза к данным космомониторинга. В настоящее время данный инструмент используют на постоянной основе для андеррайтинга, сопровождения договоров страхования урожая и урегулирования убытков 20 из 25 агростраховщиков НСA [5].

По данным НСА, в 2016 г. осуществлялся мониторинг 18 основных зернопроизводящих регионов, в числе которых Ростовская, Белгородская и Воронежская области, Краснодарский и Ставропольский края, республики Татарстан, Башкирия и другие регионы РФ.

Важности, востребованности и законодательному закреплению данных космического мониторинга в сфере сельскохозяйственного страхования России было посвящено совещание, которое прошло в Центральном банке РФ осенью 2016 г. [7], на котором присутствовали представители Минфина РФ, Минсельхоза, Минэкономразвития, Росгидромета, НCA, ряда отраслевых союзов сельхозпроизводителей, страховых компаний - членов НСА.

На данном совещании в Банке России анализировался наработанный опыт и возможности IT-инструментов, применяемых в мировой практике и в практике российских агростраховщиков. В том числе были представлены результаты тестирования мобильного инструмента «Инспектор полей».

Теперь Банк России и Национальный союз агростраховщиков разрабатывают документ, регламентирующий порядок урегулирования убытков в агростраховании с господдержкой. Новый порядок планируется разработать как отдельный документ, который будет отвечать требованиям простоты и прозрачности.

Думается, что ключевым условием обеспечения прозрачности в новом порядке возмещения вреда по договорам агрострахования, осуществляемом с государственной поддержкой, станут именно данные космического мониторинга.

\section{Выводы}

Подводя итог настоящему исследованию, следует заключить, что обоснованность и необходимость применения космического мониторинга при страховании посевов очевидна. Данная инновация получила широкое распространение в сельскохозяйственной страховой практике на глобальном уровне, начинает получать справедливую востребованность и в нашей стране.

До применения метода космического мониторинга при страховании урожая на всех его этапах существовала практика привлечения экспертов. К сожалению, представляемые ими заключения не всегда носили объективный характер: сказывался «человеческий фактор»; присутствовал конфликт интересов; отсутствовала возможность объективной оценки риска.

Благодаря космическому мониторингу и съемке с беспилотных летательных аппаратов можно составить карту реальной структуры посевов, отследить выполнение техно- 
логических операций на полях, а также диагностировать последствия опасных природных явлений, таких как засуха, ливни, град, вымерзание, приводящих к гибели посевов [4]. Эта информация помогает объективно решить вопросы, связанные с фиксацией страховых случаев и выплатой страховых компенсаций, связанных с потерей урожая.

Таким образом, как усматривается из проведенного нами анализа, обеспечение прозрачности правоотношений в сфере сельскохозяйственного страхования, осуществляемого с государственной поддержкой, следует начать с внесения соответствующих изменений в Федеральный закон от 25.07.2011 г. № 260-Ф3 (ред. от 23.06.2016 г.) «О государственной поддержке в сфере сельскохозяйственного страхования и о внесении изменений в Федеральный закон “О развитии сельского хозяйства"» [9], а именно предлагаем часть 1 статьи 5 данного закона дополнить словами: «Экспертиза проводится независимыми экспертами на основании обследования объектов страхования, если обследование возможно на момент проведения экспертизы, а также на основании представленных страховщиком и (или) страхователем документов и материалов, в том числе авиационного и космического мониторинга сельскохозяйственных культур» [8].

\section{СПИСОК ЛИТЕРАТУРЫ}

1. Гершензон, В. [Слово главного редактора] / В. Гершензон // Земля из космоса : наиболее эффективные решения. - Зима 2010. - Вып. 4. - С. 1.

2. Иншакова, А. О. Унифицированное правовое поле инновационного экономического развития и нанотехнологий региональных интеграционных объединений: ЕС, ЕВРАЗЭС, СНГ / А. О. Иншакова // Власть Закона. - 2012. - № 2 (10). - С. 22-34.

3. Использование данных ДЗ3 для мониторинга ЧС в паводкоопасный период / В. Ю. Ромасько, А. Н. Борисевич, С. И. Миськив, В. В. Иванов // Земля из космоса : наиболее эффективные решения. Зима 2010. - Вып. 4. - С. 36-43.

4. Коломин, Е. В. Взаимодействие государства и страховой системы в возмещении и предупреждении ущерба от стихийных бедствий и катастроф / Е. В. Коломин, В. Ю. Балакирева // Финансы. 2011. -№ 11. - С. 44.

5. Космические наблюдения лягут в фундамент системы урегулирования убытков в агростра- ховании с господдержкой в РФ. - Электрон дан. 28 октября 2016 г. - Режим доступа: http:// www.finmarket.ru/insurance/?nt=1\&id=4400695 (дата обращения: 18.10.2018). - Загл. с экрана.

6. Основы государственной политики в области использования результатов космической деятельности в интересах модернизации экономики Российской Федерации и развития ее регионов на период до 2030 года : (утв. Президентом РФ 14.01.2014 г. № Пр-51). - Электрон. дан. - Режим доступа: http://www.consultant.ru/cons/cgi/online. cgi? $\mathrm{req}=$ doc\&base $=$ LAW $\& \mathrm{n}=158322 \&$ fld $=134 \& \mathrm{dst}=$ $1000000001,0 \& \mathrm{rnd}=0.08093749079853296 \# 0370$ 24224549531937 (дата обращения: 18.10.2018). - Загл. с экрана.

7. Пресс-релиз: НСА представил Банку России возможности космических технологий в агростраховании. - Электрон. дан. - Режим доступа: http://www.asn-news.ru/press_release/24740 (дата обращения: 18.10.2018). - Загл. с экрана.

8. Ускова, М. С. Способы модернизации законодательства в сфере сельскохозяйственного страхования, осуществляемого с государственной поддержкой / М. С. Ускова // Евразийская адвокатура. 2017. - № 6 (31). - С. 115-117.

9. Федеральный закон от 25.07.2011 № 260-Ф3 (ред. от 23.06.2016) «О государственной поддержке в сфере сельскохозяйственного страхования и о внесении изменений в Федеральный закон "О развитии сельского хозяйства”». - Электрон. дан. - Режим доступа: http://www.consultant.ru/cons/cgi/ online.cgi?req $=$ doc\&base $=$ LAW $\& n=200212 \&$ rnd $=290$ $511.2547517905 \& \mathrm{dst}=14 \& \mathrm{fld}=134 \# 0$ (дата обращения: 18.10.2018). - Загл. с экрана.

10. Щербаков, В. В. Государственно-частное партнерство в страховании сельскохозяйственных рисков : автореф. дис. ... канд. экон. наук : 08.00.10 / Щербаков Виктор Владимирович. - М., 2010. - 19 с.

\section{REFERENCES}

1. Gershenzon V. Slovo glavnogo redaktora [Chief Editor's Word]. Zemlya iz kosmosa: naibolee effektivnye resheniya [Earth from Space: The Most Effective Solutions], 2010, iss. 4, p. 1.

2. Inshakova A.O. Unifitsirovannoe pravovoe pole innovatsionnogo ekonomicheskogo razvitiya $i$ nanotekhnologiy regionalnykh integratsionnykh obyedineniy: ES, EVRAZES, SNG [Unified Legal Field of Innovative Economic Development and Nanotechnology of Regional Integration Associations: EU, EURASEC, CIS]. Vlast Zakona, 2012, no. 2 (10), pp. 22-34.

3. Romasko V.Yu., Borisevich A.N., Miskiv S.I., Ivanov V.V. Ispolzovanie dannykh DZZ dlya 
monitoringa ChS v pavodkoopasnyy period [The Use of Remote Sensing Data for Monitoring of Emergencies in the Flood Hazard Period]. Zemlya iz kosmosa: naibolee effektivnye resheniya [Earth from Space: The Most Effective Solutions], 2010, iss. 4, pp. 36-43.

4. Kolomin E.V., Balakireva V.Yu. Vzaimodeystvie gosudarstva i strakhovoy sistemy v vozmeshchenii i preduprezhdenii ushcherba ot stikhiynykh bedstviy $i$ katastrof [The Interaction of the State and the Insurance System in the Compensation and Prevention of Damage from Natural Disasters and Catastrophes]. Finansy, 2011, no. 11, p. 44.

5. Kosmicheskie nablyudeniya lyagut $v$ fundament sistemy uregulirovaniya ubytkov $v$ agrostrakhovanii s gospodderzhkoy $v R F$ [Space Observations Will Form the Foundation of a Claims Settlement System in Agricultural Insurance with State Support in the Russian Federation]. 28 October 2016. URL: http://www. finmarket.ru/insurance/ ?nt=1\&id=4400695 (accessed 18 October 2018).

6. Osnovy gosudarstvennoy politiki v oblasti ispolzovaniya rezultatov kosmicheskoy deyatelnosti $v$ interesakh modernizatsii ekonomiki Rossiyskoy Federatsii $i$ razvitiya ee regionov na period do 2030 goda: (utv. Prezidentom RF 14.01.2014 g. № Pr51) [The Foundations of the State Policy in the Field of Using the Results of Space Activities in the Interests of Modernizing the Economy of the Russian Federation and the Development of Its Regions for the Period until 2030: Approved by the President of the Russian Federation on 14 January 2014 No. Pr-51]. URL: http://www.consultant.ru/cons/cgi/online.cgi? $\mathrm{req}=\mathrm{doc} \&$ base $=\mathrm{LAW} \& \mathrm{n}=158322 \& \mathrm{fld}=134$
$\& \mathrm{dst}=1000000001,0 \& \mathrm{rnd}=0.08093749079853296$ \#0370 24224549531937 (accessed 18 October 2018).

7. Press-reliz: NSA predstavil Banku Rossii vozmozhnosti kosmicheskikh tekhnologiy $v$ agrostrakhovanii [Press Release: NSA Presented the Opprotunities of Space Technology in Agricultural Insurance to the Bank of Russia]. URL: http:// www.asn-news.ru/press_release/24740 (accessed 18 October 2018).

8. Uskova M.S. Sposoby modernizatsii zakonodatelstva v sfere selskokhozyaystvennogo strakhovaniya, osushchestvlyaemogo s gosudarstvennoy podderzhkoy [Ways of Modernizing Legislation in the Field of Agricultural Insurance Carried out with State Support]. Evraziyskaya advokatura, 2017, no. 6 (31), pp. $115-117$.

9. Federalnyy zakon ot 25.07.2011 № 260-FZ (red. ot 23.06.2016) «O gosudarstvennoy podderzhke $v$ sfere selskokhozyaystvennogo strakhovaniya i o vnesenii izmeneniy v Federalnyy zakon "O razvitii selskogo khozyaystva"》 [Federal Law of 25 July 2011 No. 260-FZ (amend. of 23 June 2016) 'On State Support in the Field of Agricultural Insurance and on Amending the Federal Law "On the Development of Agriculture"']. URL: http:// www.consultant.ru/cons/cgi/online.cgi? req $=$ doc\&base $=$ LAW\&n $=200212 \&$ rnd $=290511.2547517905$ $\& \mathrm{dst}=14 \& \mathrm{fld}=134 \# 0$ (accessed 18 October 2018).

10. Shcherbakov V.V. Gosudarstvenno-chastnoe partnerstvo $v$ strakhovanii selskokhozyaystvennykh riskov: avtoref. dis. ... kand. ekon. nauk [PublicPrivate Partnership in Insurance of Agricultural Risks. Cand. econ. sci. abs. diss.]. Moscow, 2010. 19 p.

\section{Information about the Author}

Marina S. Uskova, Senior Lecturer, Department of Civil and International Private Law, Volgograd State University, Base Department of the Southern Scientific Center of the Russian Academy of Sciences, Prosp. Universitetsky, 100, 400062 Volgograd, Russian Federation, advokatuskova@mail.ru, https:// orcid.org/0000-0002-3438-1257

\section{Информация об авторе}

Марина Сергеевна Ускова, старший преподаватель кафедры гражданского и международного частного права, Волгоградский государственный университет, базовая кафедра ЮНЦ РАН, просп. Университетский, 100, 400062 г. Волгоград, Российская Федерация, advokatuskova@mail.ru, https://orcid.org/0000-0002-3438-1257 